\title{
Food intake of grazing ruminants with emphasis on Mediterranean grazing lands
}

\author{
AS Nastis 1, R Cordesse 2 \\ ${ }^{1}$ Department of Range and Wildife Science, University of Thessaloniki, Greece \\ ${ }^{2}$ Chaire de Zootechnie, Unité de Zootechnie Méditerranéenne. Place Viala, Montpellier, France
}

\begin{abstract}
Summary - Mediterranean grazing lands provide a complex fodder resource. Determination of ruminants food intake is laborious because of many interactions between plants, animals and environmental factors. The various techniques used for estimating intake are reviewed, they all have a relatively low precision. Even for the estimate based on the daily faecal output the main difficulty is diet sampling and diet digestibility. The interest of indicators is discussed. Existing data about lignin are not conclusive whereas many authors show promising results with chromic oxide. Alkanes and nitrogen faecal index still need a cautions use. The ingestive behaviour can also give intake estimates provided that accurate bite size figures can be obtained, otherwise measurements of the intensity of muscle current during swallowing can be attempted.
\end{abstract}

\section{Introduction}

In the past decades considerable knowledge has been accumulated in the area of defining and understanding the mechanisms which monitor and control feed intake. The desire to further understand these mechanisms is stimulated by the expected increased in animal production, since production is directly related to ingestion beyond maintenance requirements. Regardless of the complexity of mechanisms monitoring and controlling voluntary intake, it is well established that all decisions when to terminate grazing are taken by the grazer depending on forage characteristics, while other external factors play a secondary role.

On the other hand, intake measurement techniques for grazing animals seem to be another barrier in making reliable estimates of the food ingested. Such measurements are vital for evaluating the energy balance of the animals and consequently their usable output as well as for evaluating the productiveness of animal genotypes. Despite the effort devoted to improving accuracy and precision of intake procedures, estimates vary as much as 15 to $25 \%$ from the real intake value.

The purpose of this paper is to examine the factors affecting intake at pasture and methods used to determine consumption of grazing animals with emphasis on the Mediterranean zone (especially in the case of complex vegetations).

\section{Factors affecting intake at pasture}

In pastures where forage is of high quality (Campling, 1964) or when supply is not limited (Nastis, personal communication) intake is proportional to both the time spent grazing and the efficiency of grazing activity. In such condition the gut filling effect does not seem to interfer with the level of intake. Efficiency of consumption is then directly linked with biting rate and bite size. This has been documented by Forbes and Coleman (1987) and Ungar et al (1991) for grasslands and by Bourbouze (1980), and Meuret et al (1985) for rangelands with complex vegetation. However, in conventional grazing trials where forage on offer is of moderate to low digestibility (below $65 \%$ ) (Conrad et al, 1964; Van Soest, 1965) as is usually the case in mediterranean type rangelands, intake is expected to be more closely related to digestibility. Corbett et al (1963) working with cattle reported that intake declines as digestibility decreases with vegetation maturation.

Yiakoulaki and Nastis (1995) have demonstrated that intake for mediterranean pastures with complex vegetation structure is highly correlated with most of the diet quality characteristics for each period separately. However, when data from a variety of pastures and from all seasons were tested together, nor digestibility neither NDF or lignin content were correlated with intake. It is well established that intake is favoured by the increased proportions 
of leaves from forbs and shrubs since their digestion rate (Short et al, 1974) and passage rates (Ingalls et al, 1966; Milchunas et al, 1978) are much higher compared to leaves and stems of grasses. This is partially attributed to the lower NDF content at comparable stages of maturity (Huston et al, 1981). This indicates that the interaction between forage classes and maturity stages is the main interfering parameter. Therefore, feeding strategy and diet composition seems to have a definite impact on intake. Diet composition can be determined either by direct observation (Meuret et al, 1985) by rumen content analysis (Cordesse, 1994) or by faeces compositions studies (Holechek et al, 1982). Small ruminants and especially goats with their high selection ability have been proven to perform better in relatively hostile pasture environments with complex vegetations structure.

\section{Methods for estimating intake of grazing animals}

\section{Sward measurement techniques}

Many variations of this technique have been tested but non seems to provide acceptable accuracy. Even for seeded pastures (Nastis, personal communication), herbage weight variation is very high. This variation is directly transferred to intake estimates for which two such herbage estimates are needed. Intake estimates by Walters and Evans (1979) and Meijs et al (1982) as reported by Leaver (1985) (Table 1) vary from minimum estimates to the maximum estimates of intake by $71 \%$. For Mediterranean natural pastures this variation is expected to be much higher and thus intake estimates based on pasture measurements are highly variable.

\section{Animal weight before and after grazing}

This method involves weighing animals before and after grazing, while faeces and urine are collected. For estimation of water evaporation loss, harnessed but non grazing animals are weighed. The weak points are first that water content of forage samples deviate greatly when intense selection is practised, as is the case for Mediterranean forages and secondly the method can be applied only for very short duration grazing.

\section{Total collection of faeces and digestibility estimates}

The daily DM intake (DMI) can theoretically be calculated by means of the following relationship, using an estimate of the daily DM faecal output:

$\mathrm{DMI}$ = faecal DM / (1-DM digestibility)

This is the most reliable procedure for estimating intake, although all parameters involved in its estimation introduce their degree of variation, yielding an overall bias as high as $25 \%$ of the actual value. Not all animals sustain carrying a faecal bag. The aberant ones have to be excluded, otherwise results would be inconclusive. Behaviour of all animals would be modified when carrying faecal bags for extended periods. In order to reduce the load of the bag for female animals urine has to be diverted with flaps. Variation of faeces production (Table II) for harnessed and free animals seems to be insignificant (Fedele et al, 1991), when emptying faeces twice a day with minimum disturbance. However, when animals are involved in the collection process for extended periods, fatigue would have a definite impact on reduced intake. We feel that a five day collection period does not affect animal behaviour to a great extent. Beyond this time, stress problems may occur. The highest

Table I. Intake estimates based on pasture measurements (From Walters and Evans, 1979, and Meijs et al, 1982).

\begin{tabular}{|c|c|c|}
\hline \multirow{2}{*}{\multicolumn{3}{|c|}{ Walters and Evans, 1979}} \\
\hline & & \\
\hline Herbage (start) & $2687 \pm 140$ & $2596 \pm 104$ \\
\hline Herbage (end) & $1263+99$ & $1366+100$ \\
\hline \multicolumn{3}{|l|}{ Estimates } \\
\hline Intake $\mathrm{g} / \mathrm{day}^{-1} / \mathrm{kg} \mathrm{Bw}^{75}$ (max.) & 76.3 & 132.7 \\
\hline Intake g/day ${ }^{-1} / \mathrm{kg} \mathrm{BW}^{-75}(\mathrm{~min})$ & 54.0 & 95.0 \\
\hline Difference (\%) & 71 & 71 \\
\hline
\end{tabular}


variation, however, is introduced from the approximation of diet composition and digestibility. Diet sampling represents a difficult step in this method. Various techniques have been tried such as oesophagal bolus or diet simulations from either rumen particles observations (Cordesse, 1994) or biting observations on grazing animals (Meuret et al,1985). None of them are perfect; they all introduce bias. The digestibility of the collected samples is then evaluated in vitro (Aufrère and Guérin, this issue) using Tilley and Terry method (1963), fongic cellulase (Jarrige, 1970; Aufrère, 1982) or gas test (Menke and Steingass, 1988). Numerous techniques and variations have been developed to minimise this bias (sample collection and digestibility determination) while reducing labour involved. Even the most reliable techniques for conventional forage determination are unreliable for many Mediterranean shrubby species (Nastis and Meuret, 1987).

\section{Indicators and digestibility estimates}

In order to facilitate the work of total faecal collection and digestibility determination, which are also not very pleasant, experimentation has devoted tremendous effort to using indicators, so as to secure accuracy but reduce the labour involved. Perfect internal or external indicators might be indigestible, non toxic, totally recoverable in faeces and easy to determine.

-Internal indicators:

Internal indicators (lignin, chromogen etc.) are partially digested with very high variations between species and phenological stages (Fahey and Jung, 1983). The past few years there are reports allowing some room for new hope. Existing data, however, are not conclusive. Most probably some lignin fragments such as galic acid might be less digested than the lignin fraction itself which is a conglomerate of compounds. We have indications that complex lignin residues from any forage sample, when digested for extended periods, reach a constant weight. Thus it can be used as a reliable internal indicator. Leaver (1985) has information from Penning that cellulose in forage samples, when digested for extended periods reaches a constant value after about 10 days. All these ideas seem to be promising but more experimentation is needed before reaching an acceptable solution.

-External indicators:

Most of the experimental work for determining faecal output has been devoted to testing external indicators. Chromic oxide, rare earth elements and various radioactive isotopes have been used occasionally. The main problems for obtaining reliable estimate are diurnal variations and the percentage of recovery.

The most popular external indicator is $\mathrm{Cr}_{2} \mathrm{O}_{3}$, which has been used in various forms (dust, solution, impregnated paper, pellets, bound with chelating agents), but its excretion pattern as well as its recovery are rarely as expected. Estimates of faeces output from the literature range between $\pm 6 \%$ (Leaver, 1985) and $\pm 30 \%$.

Attempts have been made (Yiakoulaki, personal communication) to improve the excretion pattern of $\mathrm{Cr}_{2} \mathrm{O}_{3}$ by pelleting it with microcrystalline cellulose and $\mathrm{Mg}$ stearate (Table III). The pellets yielding more homogenous release, when tested in an in vitro trial, were the ones containing $68 \% \mathrm{Cr}_{2} \mathrm{O}_{3} 30 \%$ microcrystalline cellulose and $2 \% \mathrm{Mg}$ stearate produced under a 75 bar pressure. We also investigated a new simpler and more accurate

Table II. Faeces output (Fedele et al, 1991) when animals consumed the same food, with or without faecal bags, being in a corridor or in cages.

$\begin{array}{lr}\text { Treatments } & (\mathrm{g} / \mathrm{kg} \mathrm{BW} \cdot 75) \\ \text { Grazing } & \\ \text { Bags } & 18.31 \pm 5.6 \\ \text { «Corridor» } & 17.02 \pm 4.1 \\ \text { «Cage» } & 16.92 \pm 3.5 \\ \text { No Bags } & 31.2 \pm 2.9 \\ \text { with Bags } & 28.0 \pm 3.0\end{array}$


Table III. Pellets of $\mathrm{Cr}_{2} \mathrm{O}_{3}$ microcrystalline cellulose and $\mathrm{Mg}$ stearate produced under 50,75 and $100 \mathrm{Atm}$ pressure for reduced variation in release of $\mathrm{Cr}_{2} \mathrm{O}_{3}$.

$\begin{array}{ccc}\mathrm{Cr}_{2} \mathrm{O}_{3} & \text { Microcrystalline cellulose } & \text { Mg Stearate } \\ 30 \% & 68 \% & 2 \% \\ 49 \% & 49 \% & 2 \% \\ 68 \% & 30 \% & 2 \%\end{array}$

Table IV. Faeces production ( $\mathrm{g} / \mathrm{day}$ ) from goats grazing in shrubland by total collection and by the $\mathrm{Cr}_{2} \mathrm{O}_{3}$ indicator procedure (Yiakoulaki, personal communication).

$\begin{array}{lccc}\text { Animal } & \text { Total collection } & \mathrm{Cr}_{2} \mathrm{O}_{3} & \text { Difference (\%) } \\ \text { May } & 418 & 440 & +5,3 \\ \text { CV\% } & 15,3 & 11,2 & \\ \text { November } & 540 & 524 & -2,3 \\ \text { CV\% } & 16,5 & 12,9 & \end{array}$

method of determining $\mathrm{Cr}_{2} \mathrm{O}_{3}$ (Ashing, converting $\mathrm{Cr}$ to $\mathrm{CrO}_{4}{ }^{2-}$ by using $\mathrm{Na}_{2} \mathrm{O}_{2}$, and determining it by atomic absorption).

These pellets were tested in a digestion trial, collecting faecal samples every hour. The release of $\mathrm{Cr}_{2} \mathrm{O}_{3}$ seems to be almost linear and the precision very high. Then two field experiments were conducted dosing animals with the same pellets as above. The estimates of faeces production (Table IV) deviated by $2,3 \%$ in May and by $+5.3 \%$ in November. Estimates of intake determined with the two methods presented in table $V$ indicate that this procedure can be considered very reliable.

Dosing animals daily or twice a day may be applicable for housed animals or those grazing in small enclosures. Such a practice, which requires intensive labor, is not convenient when animals graze in extensive rangelands. Parker et al (1990) and Ellis et al (1981) have tested the "captec" one dose $\mathrm{Cr}_{2} \mathrm{O}_{3}$ capsules. These are $\mathrm{Cr}_{2} \mathrm{O}_{3}$ pellets housed in a plastic cover for homogenous release of the indicator over 30 to 100 days, depending on the model.
The results obtained up to the present are not as expected. Stabilization of concentration within the rumen (Graham 1988, Parker et al, 1989; Lee et al, 1990; Luginbuhl et al, 1994) varies from 3-8 days depending on animal species. Thereafter, variation in feeding regimes (Parker et al, 1990; Lee et al, 1990) is insignificant $(4-8 \%)$, while for rapidly ingested feeds (Hatfield et al, 1991) an underestimation of faecal production was observed. No effect of live weight between 27 to $52 \mathrm{~kg}$ on the reluse rate was observed (Luginbuhl et al, 1994). These characteristics allow their use in flocks grazing in heterogeneous pastures. Although labour involved with the use of "captec" capsules is drastically reduced and large numbers of animals can be handled at once, confidence has not been established yet (Hatfield et al, 1991) for its precision compared to the twice daily dosing method. For increasing accuracy when using this technique it is recommended to use faecal bags, to on a small number of animals.

We also tested erbium ( $E r$ ) as one dose

Table V. Intake (g DM/kg BW.75) of goats grazing in evergreen shrubland (Yiakoulaki, personal communication).

$\begin{array}{lcc} & \text { Total collection } & \mathrm{Cr}_{2} \mathrm{O}_{3} \\ \text { May } & 50.8 \pm 2.6 & 53.6 \pm 2.1 \\ \text { November } & 46.9 \pm 2.2 & 46.7 \pm 1.9\end{array}$


indicator. Its concentration "C $\mathrm{C}$ " at time "t" is given by the equation: $\mathrm{C}_{\mathrm{t}}=\mathrm{C}_{\mathrm{O}} \mathrm{e}^{-(\mathrm{i} / \mathrm{v}) \mathrm{t}}$ (where $e=$ base of natural logarithm, $i=$ rate of intake, $\mathrm{v}=$ rumen volume). Although $\mathrm{Er}$ quantification by flame spectroscopy is convenient and very accurate, the results obtained not accurately approximate to actual intake. The limitation might be overcome by using a two compartment model, one for the ascending part of the curve and one for the descending. -Internal and external indicators:

Alkanes, saturated carbonhydrates, are promising indicators for simple diets (Dove and Mayes, 1991) in spite of their partial digestibility and the difficulties both for their determination (gas chromatography) and the diet sampling (variable concentrations depending on the part of the plant and the hour of the day).

Natural alkanes are odd chained and not the synthetic ones. Added to the diet, the last act as external indicators. Their digestibility, though low, can be measured thus giving an estimate of internal alkanes digestibility. A compensatory effect is obtained concerning the faecal recovery errors. The odd natural alkanes gives us the vegetal diet digestibility, the faecal outpout being obtained by the faecal determination of the synthetic external alkanes. Alkanes are of current use in the grazing studies on simple vegetations where the number of species is low (Newman et al, 1995). They are not yet used in heterogenous rangelands with more than ten vegetal species. However attempts could be made in some rangeland situations where the major part of the diet contains only a low number of species (3 to 5) (Dove and Moore, 1995).

\section{Water consumption}

It has been reported that consumption is very closely related with the amount of water consumed (Hyder, 1970). However, discrepancies occur due to variable water content of forage as well as weather condition variations. Thus this method can be used only for rough approximations.

\section{Nitrogen faecal index}

This method allows accurate calculation of the diet digestibility in the case if low tannin fodder resources. From the equation established by Demarquilly et al (1981)

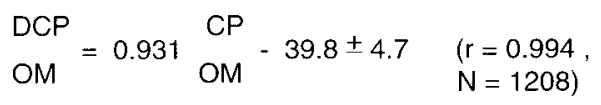

OM digestibility can be calculated :

$$
\begin{aligned}
& \text { OM digestibility }=1-0.069 \begin{array}{l}
\mathrm{CPi} \\
\mathrm{CPf}
\end{array} \\
& \mathrm{i}=\text { ingested } \\
& \mathrm{f}=\text { excreted }
\end{aligned}
$$

$\mathrm{CPi}$ is evaluated from the simulated diet samples. Its precision depends on the quality of the simulation but the influence of this parameter on OM digestibility is low because of its low coefficients $(0.069$ ).

This method is tested occasionally, yielding results with acceptable accuracy, only when used under a given set of pasture conditions. Pasture composition variations greatly affect its prediction power.

\section{Ingestive behaviour}

Intake can be estimated by using behavioural measurements which imply the least interference with the pasture and the animal. I $=$ Grazing Time $(\mathrm{GT})$ * Biting Rate $(\mathrm{BR})$ * Bite Size (BS). The measurement of GT can be done very precisely and accurately with vibracorders or electronic devices. Continuous recording or that done at $10 \mathrm{~min}$ intervals (Jamieson, 1975) does not affect precision (Table VI). Biting rate can be also determined by the use of modern electronic devices or even by ocular measurements, at some time intervals, with acceptable accuracy. In order to

Table VI. Recording interval for grazing time (Jamieson, 1975).

$\begin{array}{lc}\text { Interval } & \text { Grazing time }(h) \\ \text { Continuous } & 7.50 \\ 5 \text { min interval } & 7.47 \\ 10 \text { min interval } & 7.42 \\ \text { S.E. } & 0.13\end{array}$


Table VII. Grazing time (GT) and biting rate (BR) in relation to forage availability (Intake was almost constant) (Nastis, personal communication).

\begin{tabular}{|c|c|c|c|c|c|}
\hline Trial & 1 & II & & IV & V \\
\hline Biomass (kg/ha) & 919 & 758 & 534 & 311 & 143 \\
\hline GT $(\min / d)$ & $380 \mathrm{c}$ & $423 c$ & $521 \mathrm{~b}$ & $531 \mathrm{~b}$ & $656 a$ \\
\hline $\mathrm{BR}(\mathrm{b} / \mathrm{min})$ & 37 & 40 & 39 & 45 & 50 \\
\hline
\end{tabular}

The main problem in determining intake by this procedure is the quantification of bite size. (Table VIII). Very high variations in bolus weight also have been reported by various researchers (Table IX) while Wallis De Vries (1995) reported that bite size $(\mathrm{mg} / \mathrm{cm} 2)$ was curvilinearly related with plugging size $(\mathrm{g})$.

Table VIII. Variation in bite size

Stobbs $(1973)$
Stobbs $(1973)$
Jamieson $(1975)$

$130 \mathrm{mg} / \mathrm{bite}$ (unfertilized)
$390 \mathrm{mg} / \mathrm{bite}$ (fertilized)
$70-1610 \mathrm{mg} / \mathrm{bite}($ temperate sward)

Table IX.Variations in bite size and bolus weight as reported by various researchers.

\author{
Gill et al (1966) \\ Gill et al (1966) \\ Stuth and Angell (1982) \\ Stuth and Angell (1982)
}

\author{
$11 \mathrm{~g} /$ bolus \\ $22-28 \mathrm{~g} / \mathrm{bolus}$ \\ $4.2 \mathrm{~g} / \mathrm{bolus}$ (summer) \\ $4.4 \mathrm{~g}$ /bolus (winter)
}

maintain constant intake (Nastis, 1979) animal can vary both grazing time and biting rate according to resources available (Table VII).

Bite size for browsers has been proposed by Meuret (1989), Dumont et al (1995) to be measured by defining 6 to 8 different bite sizes. This procedure would better approximate bite size and thus estimates of intake can be improved. We feel that by measuring the electric currents in the muscles caused by bolus ingestion, the procedure may be simplified and the accuracy may be improved.

\section{Conclusions}

1. Food consumption is controlled by many plant, animal and environmental factors as well as their interaction. In the Mediterranean zone, where forage quality is generally low, intake is predominantly controlled by gut fill while the effect of the other intake controlling factors is occasional.

2. Determination of intake for grazing animals is laborious, usually unpleasant and therefore time consuming and expensive.

3. Techniques available for studying intake of grazing animals are characterised by relatively low accuracy and precision. Errors in partial components measured contribute to higher overall variation. In order to increase precision beyond the greater interest and attention, efficient experimental designs have to be used to reduce the variation between parameters.

4. Numerous attempts to estimate intake have been made, with a variety of procedures. Their approximation, being on the average $\pm 25 \%$ of the real, is far from any acceptable approximation.

5. Sward intake estimates methods are preferred only when dealing with uniform pastures for short term grazing duration.

6. Animal based intake determination methods are preferred when herbage intake and digestibility are relatively constant and measurements are done after adjusting animals to pasture.

7. More research is needed to develop new, precise and less expensive techniques.

8. Prolonged digestion resulting in constant lignin weight or determination of partial indigestible fragments of lignin might be better internal indicators.

9. The development of devices for more uniform indicator release and utilisation of more easily quantifiable external indicators are needed.

10. Testing a one dose indicator with a two 
compartment model might be promising.

11. Modern electronic techniques make it possible to monitor details of behaviour. Hopefully, the bolus size problem will be overcome for improving accuracy of intake estimates by measuring intensity of muscle current during swallowing.

12. Intake measurements should be made only when they are really needed and can be performed with an acceptable degree of accuracy.

\section{Literature cited}

Aufrère J (1982) Etude de la prévision de la digestibilité des fourrages par une méthode enzymatique. Ann Zootech 31, 111-130

Bourbouze A (1980) Utilisation d'un parcours forestier pâturé par des caprins. Fourrages $82,121-144$

Campling RC (1964) Factors affecting the voluntary intake of grass. Nutr Soc Proc 23, 80-87

Conrad HR, Pratt AD, Hibbs JW (1964) Regulation of feed intake in dairy cows. I. Changes in importance of physical and physiological factors with increasing digestibility. J Dairy Sci 47, 54-62

Corbett JL, Langlands JP, Reid GW (1963) Effects of season on growth and digestibility of herbage on intake by grazing cows. Anim Prod 5, 119-129

Cordesse R (1994) Mise au point d'une méthode d'identification de la composition du régime alimentaire des herbivores sur des milieux végétaux complexes. Ann Zootech 43, 34

Demarquilly C, Grenet E, Andrieu J (1981) Les constituants azotés des fourrages et la prévision de la valeur azotée des fourrages. In: Prévision de la valeur nutritive des aliments des ruminants (C Demarquilly, ed) INRA Publications, Paris, 119-127

Dove $H$, Mayes RW (1991) The use of plant wax alkanes as marker substances in studies of the nutrition of herbivores: a review. Aust $J$ of Agric Res 42, 913-952

Dove $H$. Moore AD (1995) Using a least-squares optimisation procedure to estimate botanical composition based on the alkanes of plant cuticular wax. In: Workshop Alkan, Aberdeen, $18 \mathrm{p}$

Dumont B, Meuret M, Prud'hon M (1995) Direct observation of biting for studying grazing behaviour of goats and llamas on garrigue rangelands. Small Ruminant Research 16, 27-35

Ellis KJ, Laby RH, Burns RG (1981) Continuous controlled release administration of chromic oxide to sheep. Proc Nutr Soc Austr 6, 145

Fahey GC, Jung HG (1983) Lignin as a marker in digestion studies: a review. J Anim Sci 57, 220225

Fedele V, Rubino R, Claps S, Di Trana A (1991) Intake measurements in grazing experiments; Comparison of different methods. FAO Network on sheep and goat production, meeting, Ostersund, Sweden

Forbes TDA, Coleman SW (1987) Herbage intake and ingestive behaviour of grazing cattle as influenced by variation in sward characteristics. In: Proc Special Session Grazing Land Res at the Plant, Animal Interface, Morrilton, USA, 141152

Gill J. Campling RG, Westgarth DR (1966) A study of chewing during eating in the cow. Brit $J$ Nutr 20 . $13-25$

Graham J (1988) The use of slow release chromic oxide capsules (Captec chrome) to mesure animal intake. Research review 1987-1988. Past Res Inst Hamilton, Victoria, 91-92

Hatfield PG, Walker GW, Glimp HA (1991) Comparing the captec bolus to chromic oxide dosed twice daily using sheep in confinement. $J$ Range Manage 44, 408-409

Holechek JL, Vavra M, Pieper RD (1982) Botanical composition determination of range herbivore diets: a review. J Range Manage 35, 309-315

Huston JE, Rector BS, Merrill LB, Engdall BS (1981) Nutritive value of range plants in the Edwards plateau region of Texas. Texas Agr Exp Sta Bull $1357,15 p$

Hyder DN (1970) Water intake by cattle as a measure of forage intake and quality. In: Range and wildife habitat evaluation. A Res Symp Miscel public, Forest Service, Washington, DC, 1144

Ingalls JR, Thomas JW, Tesar MG, Carpenter DL (1966) Relations between ad libitum intake of several forages and gut fill. $J$ Anim Sci $25,283-$ 289

Jamieson WS (1975) Studies on the herbage intake and grazing behaviour of cattle and sheep. Ph D thesis, Univ of Reading, $187 \mathrm{p}$

Jarrige R (1970) Méthode de prévision de la valeur alimentaire des fourrages. Fourrages $42,1-20$

Leaver JD (1985) Herbage intake handbook. Brit Grass Soc $143 p$

Lee GJ, Atkins KD, Mortimer SI (1990) Use of controlled release devices as a technique to estimate pasture intake by grazing sheep. Proc 8th Austr Assoc Anim Breed and Genet 147-150

Luginbuhl JM, Pond KR, Burns JC, Fisher DS (1994) Evaluation of the Captec Controlled-release chromic oxide capsule for fecal output determination in sheep. J Anim Sci 72, 13751380

Meijs JAC, Walters RJK, Keen A (1982) Sward Methods. In: Herbage intake handbook (JD 
leaver, ed) British Grassland Soc, Hurley, Great Britain

Menke $\mathrm{KH}$, Steingass $\mathrm{H}$ (1988) Estimation of the energetic feed value obtained from chemical analysis and in vitro gas production using rumen fluid. Anim Res Deve/28, 7-55

Meuret M (1989) Utilisation of native Mediterranean fodder trees by dairy goats. In: Proc XVI Int Grass Congr Nice, France, 941-942

Meuret M, Bartiaux-Thill N, Bourbouze A (1985) Evaluation de la consommation d'un troupeau de chèvres laitières sur parcours forestier - Méthode d'observation directe des coups de dent Méthode du marqueur oxyde de chrome. Ann Zootech 34, 159-180

Milchunas DG, Dyer MI, Walimo DC, Johnson DE (1978) In vivo-in vitro relationships of Colorado mule deer forages. Colorado Div Wildife spec Rep 43, Fort Collins, $46 \mathrm{p}$

Nastis AS, Meuret M (1987) Methods of estimation of nutritive value and intake of forage by goats. Agriculture EUR 11893 FR-EN , 142-158

Newman JA, Thompson WA, Penning PD, Mayes RW (1995) Least-squares estimation of diet composition from $\mathrm{n}$-alkanes in herbage and faeces using matrix mathematics. Aust $J$ Agri Res 46, 793-805

Parker WJ, Mc Cutcheon SN, Carr DH (1989) Effect of herbage type and level of intake on the release of chromic oxide from intraruminal controlled release capsules in sheep. NZJ Agric Res 32, 537-546

Parker WJ, Morris ST, Vincent GL, Mc Cutcheon SN (1990) Intraruminal chromium controlled release capsules for measuring herbage intake in ruminants: a review. Proc NZ Soc Anim Prod 50,
437-442

Short HL, Blair RM, Segelquist CA (1974) Fiber composition and Forage digestibility by small ruminants. J Wild Manage 38, 197-209

Stobs TH (1973) The effect of plant structure on the intake of tropical pastures. I - Variation in the bite size of grazing cattle. Aust $J$ Agric Res 24, 809819

Stuth JW. Angell RF (1982) Effect of seasonal herbage allowance on bolus weights of cattle. $J$ Range Manage 35(2), 163-165

Tilley JMA, Terry RA (1963) A two stage technique for in vitro digestion of forage crops. $\mathrm{J} \mathrm{Br}$ Grass Soc 18, 104-111

Ungar ED, Genizi A, Demment MW (1991) Bite dimension and herbage intake by cattle grazing short hand - contructed swards. Agron J 83, 973978

Van Soest $P$ (1965) Use of detergents in analysis of fibrous feeds. III. Study of effects of heating and drying on yield of fiber and lignin in forages. Assoc Off Agr Chem J 48, 785-790

Wallis De Vries M (1995) Estimating forage intake and quality in grazing cattle: a reconsideration of the hand-plucking method. J Range Manage 48, 370-375

Walters RJK, Evans EM (1979) Evaluation of sward sampling technique for estimating herbage intake by grazing sheep. Grass and Forage Sci 34, 3744

Yiakoulaki MD, Nastis NS (1995) Intake by goats grazing kermes oak shrublands with varying cover in Northern Greece. I Small Ruminant Research 17(3), 223-228 